\title{
Common fixed point results for contractive mappings in complex valued metric spaces
}

\author{
Jamshaid Ahmad ${ }^{1}$, Akbar Azam ${ }^{1}$ and Satit Saejung ${ }^{2,3 *}$
}

\author{
${ }^{*}$ Correspondence: \\ saejung@kku.ac.th \\ 2Department of Mathematics, Khon \\ Kaen University, Khon Kaen, 40002, \\ Thailand \\ ${ }^{3}$ The Centre of Excellence in \\ Mathematics, Commission on \\ Higher Education (CHE), Sri \\ Ayudthaya Road, Bangkok, 10400 \\ Thailand \\ Full list of author information is \\ available at the end of the article
}

\begin{abstract}
In this paper, we obtain some common fixed point results for the mappings satisfying rational expressions on a closed ball in complex valued metric spaces. Our results improve several well-known conventional results.

MSC: $47 \mathrm{H} 10 ; 54 \mathrm{H} 25$
\end{abstract}

Keywords: common fixed point; contractive type mapping; complex valued metric space

\section{Introduction and preliminaries}

Azam et al. [1] introduced new spaces called complex valued metric spaces and established the existence of fixed point theorems under the contraction condition. Subsequently, Rouzkard and Imdad [2] established some common fixed point theorems satisfying certain rational expressions in complex valued metric spaces which generalize, unify and complement the results of Azam et al. [1]. Sintunavarat and Kumam [3] obtained common fixed point results by replacing constant of contractive condition to control functions. Recently, Klin-eam and Suanoom [4] extend the concept of complex valued metric spaces and generalized the results of Azam et al. [1] and Rouzkard and Imdad [2]. For more on fixed point theory we refer the reader to [4-26].

The aim of this article is to extend and improve the conditions of contraction from the whole space to closed ball and establish the common fixed point theorems which are more general than the results of Klin-eam and Suanoom [4], Rouzkard and Imdad [2], and Azam et al. [1] on complex valued metric spaces.

Let $\mathbb{C}$ be the set of complex numbers and $z_{1}, z_{2} \in \mathbb{C}$. Define a partial order $\precsim$ on $\mathbb{C}$ as follows:

$$
z_{1} \precsim z_{2} \quad \text { if and only if } \operatorname{Re}\left(z_{1}\right) \leq \operatorname{Re}\left(z_{2}\right) \text { and } \operatorname{Im}\left(z_{1}\right) \leq \operatorname{Im}\left(z_{2}\right) \text {. }
$$

It follows that $z_{1} \precsim z_{2}$ if and only if one of the following conditions is satisfied:

(i) $\operatorname{Re}\left(z_{1}\right)=\operatorname{Re}\left(z_{2}\right)$ and $\operatorname{Im}\left(z_{1}\right)<\operatorname{Im}\left(z_{2}\right)$,

(ii) $\operatorname{Re}\left(z_{1}\right)<\operatorname{Re}\left(z_{2}\right)$ and $\operatorname{Im}\left(z_{1}\right)=\operatorname{Im}\left(z_{2}\right)$,

(iii) $\operatorname{Re}\left(z_{1}\right)<\operatorname{Re}\left(z_{2}\right)$ and $\operatorname{Im}\left(z_{1}\right)<\operatorname{Im}\left(z_{2}\right)$,

(iv) $\operatorname{Re}\left(z_{1}\right)=\operatorname{Re}\left(z_{2}\right)$ and $\operatorname{Im}\left(z_{1}\right)=\operatorname{Im}\left(z_{2}\right)$.

@2014 Ahmad et al:; licensee Springer. This is an Open Access article distributed under the terms of the Creative Commons Attribution License (http://creativecommons.org/licenses/by/2.0), which permits unrestricted use, distribution, and reproduction in any medium, provided the original work is properly cited. 
In particular, we will write $z_{1} \precsim z_{2}$ if $z_{1} \neq z_{2}$ and one of (i), (ii), and (iii) is satisfied and we will write $z_{1} \prec z_{2}$ if only (iii) is satisfied. Note that

$$
\begin{aligned}
& 0 \precsim z_{1} \precsim z_{2} \quad \Longrightarrow \quad\left|z_{1}\right|<\left|z_{2}\right|, \\
& z_{1} \precsim z_{2}, \quad z_{2} \prec z_{3} \quad \Longrightarrow \quad z_{1} \prec z_{3} .
\end{aligned}
$$

Definition 1 Let $X$ be a nonempty set. Suppose that the mapping $d: X \times X \rightarrow \mathbb{C}$ satisfies:

(1) $0 \precsim d(x, y)$ for all $x, y \in X$; and $d(x, y)=0$ if and only if $x=y$;

(2) $d(x, y)=d(y, x)$ for all $x, y \in X$;

(3) $d(x, y) \precsim d(x, z)+d(z, y)$ for all $x, y, z \in X$.

Then $d$ is called a complex valued metric on $X$ and $(X, d)$ is called a complex valued metric space.

A point $x \in X$ is called an interior point of a set $A \subseteq X$ whenever there exists $0 \prec r \in \mathbb{C}$ such that

$$
B(x, r):=\{y \in X: d(x, y) \prec r\} \subseteq A,
$$

where $B(x, r)$ is an open ball. Then $\overline{B(x, r)}=\{y \in X: d(x, y) \preceq r\}$ is a closed ball.

A point $x \in X$ is called a limit point of $A$ whenever for every $0 \prec r \in \mathbb{C}$, we have

$$
B(x, r) \cap(A \backslash\{x\}) \neq \varnothing .
$$

A subset $A \subseteq X$ is called open whenever each element of $A$ is an interior point of $A$. A subset $B \subseteq X$ is called closed whenever each limit point of $B$ belongs to $B$. The family

$$
F:=\{B(x, r): x \in X, 0 \prec r\}
$$

is a sub-basis for a Hausdorff topology $\tau$ on $X$.

Let $\left\{x_{n}\right\}$ be a sequence in $X$ and $x \in X$. If for every $c \in \mathbb{C}$ with $0 \prec c$ there is $n_{0} \in \mathbb{N}$ such that $d\left(x_{n}, x\right) \prec c$, for all $n>n_{0}$, then $\left\{x_{n}\right\}$ is said to be convergent and $\left\{x_{n}\right\}$ converges to $x$. We denote this by $\lim _{n} x_{n}=x$ or $x_{n} \rightarrow x$. If for every $c \in \mathbb{C}$ with $0 \prec c$ there is $n_{0} \in \mathbb{N}$ such that $d\left(x_{n}, x_{m}\right) \prec c$, for all $n, m>n_{0}$, then $\left\{x_{n}\right\}$ is called a Cauchy sequence. If every Cauchy sequence is convergent in $(X, d)$, then $(X, d)$ is called a complete complex valued metric space.

Example 2 Let $X=X_{1} \cup X_{2}$ where

$$
X_{1}=\{z \in \mathbb{C}: \operatorname{Re}(z) \geq 0 \text { and } \operatorname{Im}(z)=0\}
$$

and

$$
X_{2}=\{z \in \mathbb{C}: \operatorname{Re}(z)=0 \text { and } \operatorname{Im}(z) \geq 0\} .
$$

Define $d: X \times X \rightarrow \mathbb{C}$ as follows:

$$
d\left(z_{1}, z_{2}\right)= \begin{cases}\frac{2}{3}\left|x_{1}-x_{2}\right|+\frac{i}{2}\left|x_{1}-x_{2}\right| & \text { if } z_{1}, z_{2} \in X_{1} ; \\ \frac{1}{2}\left|y_{1}-y_{2}\right|+\frac{i}{3}\left|y_{1}-y_{2}\right| & \text { if } z_{1}, z_{2} \in X_{2} ; \\ \left(\frac{2}{3} x_{1}+\frac{1}{2} y_{2}\right)+i\left(\frac{1}{2} x_{1}+\frac{1}{3} y_{2}\right) & \text { if } z_{1} \in X_{1}, z_{2} \in X_{2} ; \\ \left(\frac{1}{2} y_{1}+\frac{2}{3} x_{2}\right)+i\left(\frac{1}{3} y_{1}+\frac{1}{2} x_{2}\right) & \text { if } z_{1} \in X_{2}, z_{2} \in X_{1},\end{cases}
$$


where $z_{1}=x_{1}+i y_{1}, z_{2}=x_{2}+i y_{2} \in X$. Then $(X, d)$ is a complete complex valued metric space.

Lemma 3 [1] Let $(X, d)$ be a complex valued metric space and let $\left\{x_{n}\right\}$ be a sequence in $X$. Then $\left\{x_{n}\right\}$ converges to $x$ if and only if $\left|d\left(x_{n}, x\right)\right| \rightarrow 0$ as $n \rightarrow \infty$.

Lemma 4 [1] Let $(X, d)$ be a complex valued metric space and let $\left\{x_{n}\right\}$ be a sequence in $X$. Then $\left\{x_{n}\right\}$ is a Cauchy sequence if and only if $\left|d\left(x_{n}, x_{n+m}\right)\right| \rightarrow 0$ as $n \rightarrow \infty$.

Definition 5 [27] Two families of self-mappings $\left\{T_{i}\right\}_{1}^{m}$ and $\left\{S_{i}\right\}_{1}^{n}$ are said to be pairwise commuting if:

(1) $T_{i} T_{j}=T_{j} T_{i}$ for all $i, j \in\{1,2, \ldots, m\}$;

(2) $S_{k} S_{l}=S_{l} S_{k}$ for all $k, l \in\{1,2, \ldots, n\}$;

(3) $T_{i} S_{k}=S_{k} T_{i}$ for all $i \in\{1,2, \ldots, m\}, k \in\{1,2, \ldots, n\}$.

\section{Main result}

In our main result, we discuss the existence of the common fixed point of the mappings satisfying a contractive condition on the closed ball. This result is very useful in the sense that it requires the contractiveness of the mappings only on a closed ball instead of the whole space.

Theorem 6 Suppose that $(X, d)$ is a complete complex valued metric space and $x_{0} \in X$. Let $0 \prec r \in \mathbb{C}$ and $A, B, C, D$ and $E$ be five nonnegative reals such that $A+B+C+2 D+2 E<1$. Let $S, T: X \rightarrow X$ satisfy

$$
\begin{aligned}
d(S x, T y) \precsim & A d(x, y)+B \frac{d(x, S x) d(y, T y)}{1+d(x, y)}+C \frac{d(y, S x) d(x, T y)}{1+d(x, y)} \\
& +D \frac{d(x, S x) d(x, T y)}{1+d(x, y)}+E \frac{d(y, S x) d(y, T y)}{1+d(x, y)}
\end{aligned}
$$

for all $x, y \in \overline{B\left(x_{0}, r\right)}$. If

$$
\left|d\left(x_{0}, S x_{0}\right)\right| \leq(1-\lambda)|r|
$$

where $\lambda=\max \left\{\frac{A+D}{1-B-D}, \frac{A+E}{1-B-E}\right\}$, then there exists a unique point $u \in \overline{B\left(x_{0}, r\right)}$ such that $u=S u=$ $\mathrm{Tu}$.

Proof Let $x_{0}$ be an arbitrary point in $X$ and define

$$
x_{2 k+1}=S x_{2 k} \quad \text { and } \quad x_{2 k+2}=T x_{2 k+1}, \quad \text { where } k=0,1,2, \ldots
$$

We will prove that $x_{n} \in \overline{B\left(x_{0}, r\right)}$ for all $n \in \mathbb{N}$ by mathematical induction.

Using inequality (2) and the fact that $\lambda=\max \left\{\frac{A+D}{1-B-D}, \frac{A+E}{1-B-E}\right\}<1$, we have

$$
\left|d\left(x_{0}, S x_{0}\right)\right| \leq|r|
$$


It implies that $x_{1} \in \overline{B\left(x_{0}, r\right)}$. Let $x_{2}, \ldots, x_{j} \in \overline{B\left(x_{0}, r\right)}$ for some $j \in N$. If $j=2 k+1$, where $k=0,1,2, \ldots, \frac{j-1}{2}$ or $j=2 k+2$ where $k=0,1,2, \ldots, \frac{j-2}{2}$, we obtain by using inequality (1)

$$
\begin{aligned}
d\left(x_{2 k+1}, x_{2 k+2}\right)= & d\left(S x_{2 k}, T x_{2 k+1}\right) \\
\precsim & A d\left(x_{2 k}, x_{2 k+1}\right)+B \frac{d\left(x_{2 k+1}, T x_{2 k+1}\right) d\left(x_{2 k}, S x_{2 k}\right)}{1+d\left(x_{2 k}, x_{2 k+1}\right)} \\
& +C \frac{d\left(x_{2 k}, T x_{2 k+1}\right) d\left(x_{2 k+1}, S x_{2 k}\right)}{1+d\left(x_{2 k}, x_{2 k+1}\right)} \\
& +D \frac{d\left(x_{2 k}, T x_{2 k+1}\right) d\left(x_{2 k}, S x_{2 k}\right)}{1+d\left(x_{2 k}, x_{2 k+1}\right)} \\
& +E \frac{d\left(x_{2 k+1}, T x_{2 k+1}\right) d\left(x_{2 k+1}, S x_{2 k}\right)}{1+d\left(x_{2 k}, x_{2 k+1}\right)} .
\end{aligned}
$$

Now $x_{2 k+1}=S x_{2 k}$ implies that $d\left(x_{2 k+1}, S x_{2 k}\right)=0$, so we have

$$
\begin{aligned}
d\left(x_{2 k+1}, x_{2 k+2}\right) \precsim & A d\left(x_{2 k}, x_{2 k+1}\right)+B \frac{d\left(x_{2 k+1}, x_{2 k+2}\right) d\left(x_{2 k}, x_{2 k+1}\right)}{1+d\left(x_{2 k}, x_{2 k+1}\right)} \\
& +D \frac{d\left(x_{2 k}, x_{2 k+2}\right) d\left(x_{2 k}, x_{2 k+1}\right)}{1+d\left(x_{2 k}, x_{2 k+1}\right)} .
\end{aligned}
$$

This implies that

$$
\begin{aligned}
\left|d\left(x_{2 k+1}, x_{2 k+2}\right)\right| \leq & A\left|d\left(x_{2 k}, x_{2 k+1}\right)\right|+B \frac{\left|d\left(x_{2 k+1}, x_{2 k+2}\right)\right|\left|d\left(x_{2 k}, x_{2 k+1}\right)\right|}{\left|1+d\left(x_{2 k}, x_{2 k+1}\right)\right|} \\
& +D \frac{\left|d\left(x_{2 k}, x_{2 k+2}\right)\right|\left|d\left(x_{2 k}, x_{2 k+1}\right)\right|}{\left|1+d\left(x_{2 k}, x_{2 k+1}\right)\right|} .
\end{aligned}
$$

Since $\left|1+d\left(x_{2 k}, x_{2 k+1}\right)\right|>\left|d\left(x_{2 k}, x_{2 k+1}\right)\right|$, we have

$$
\left|d\left(x_{2 k+1}, x_{2 k+2}\right)\right| \leq A\left|d\left(x_{2 k}, x_{2 k+1}\right)\right|+B\left|d\left(x_{2 k+1}, x_{2 k+2}\right)\right|+D\left|d\left(x_{2 k}, x_{2 k+2}\right)\right| .
$$

This implies by the triangular inequality that

$$
\left|d\left(x_{2 k+1}, x_{2 k+2}\right)\right| \leq \frac{A+D}{1-B-D}\left|d\left(x_{2 k}, x_{2 k+1}\right)\right| .
$$

Similarly, we get

$$
\left|d\left(x_{2 k+2}, x_{2 k+3}\right)\right| \leq \frac{A+E}{1-B-E}\left|d\left(x_{2 k+2}, x_{2 k+1}\right)\right| .
$$

Putting $\lambda=\max \left\{\frac{A+D}{1-B-D}, \frac{A+E}{1-B-E}\right\}$, we obtain

$$
\left|d\left(x_{j}, x_{j+1}\right)\right| \leq \lambda^{j}\left|d\left(x_{0}, x_{1}\right)\right| \quad \text { for all } j \in \mathbb{N} \text {. }
$$

Now

$$
\begin{aligned}
\left|d\left(x_{0}, x_{j+1}\right)\right| & \leq\left|d\left(x_{0}, x_{1}\right)\right|+\cdots+\left|d\left(x_{j}, x_{j+1}\right)\right| \\
& \leq\left|d\left(x_{0}, x_{1}\right)\right|+\cdots+\lambda^{j}\left|d\left(x_{0}, x_{1}\right)\right|
\end{aligned}
$$




$$
\begin{aligned}
& =\left|d\left(x_{0}, x_{1}\right)\right|\left[1+\cdots+\lambda^{j-1}+\lambda^{j}\right] \\
& \leq(1-\lambda)|r| \frac{\left(1-\lambda^{j+1}\right)}{1-\lambda} \\
& \leq|r|
\end{aligned}
$$

gives $x_{j+1} \in \overline{B\left(x_{0}, r\right)}$. Hence $x_{n} \in \overline{B\left(x_{0}, r\right)}$ for all $n \in \mathbb{N}$ and

$$
\left|d\left(x_{n}, x_{n+1}\right)\right| \leq \lambda^{n}\left|d\left(x_{0}, x_{1}\right)\right|
$$

for all $n \in \mathbb{N}$. Without loss of generality, we take $m>n$, then

$$
\begin{aligned}
\left|d\left(x_{n}, x_{m}\right)\right| & \leq\left|d\left(x_{n}, x_{n+1}\right)\right|+\left|d\left(x_{n+1}, x_{n+2}\right)\right|+\cdots+\left|d\left(x_{m-1}, x_{m}\right)\right| \\
& \leq\left[\lambda^{n}+\lambda^{n+1}+\cdots+\lambda^{m-1}\right]\left|d\left(x_{0}, x_{1}\right)\right| \\
& \leq\left[\frac{\lambda^{n}}{1-\lambda}\right]\left|d\left(x_{0}, x_{1}\right)\right| \rightarrow 0 \quad \text { as } m, n \rightarrow \infty .
\end{aligned}
$$

This implies that the sequence $\left\{x_{n}\right\}$ is a Cauchy sequence in $\overline{B\left(x_{0}, r\right)}$. Therefore, there exists a point $u \in \overline{B\left(x_{0}, r\right)}$ with $\lim _{n \rightarrow \infty} x_{n}=u$.

We prove that $u=S u$. Let us consider

$$
\begin{aligned}
|d(u, S u)| \leq & \left|d\left(u, x_{2 k+2}\right)\right|+A\left|d\left(x_{2 k+1}, u\right)\right|+B \frac{\left|d\left(x_{2 k+1}, T x_{2 k+1}\right)\right||d(u, S u)|}{\left|1+d\left(u, x_{2 k+1}\right)\right|} \\
& +C \frac{\left|d\left(x_{2 k+1}, S u\right)\right|\left|d\left(u, T x_{2 k+1}\right)\right|}{\left|1+d\left(u, x_{2 k+1}\right)\right|} \\
& +D \frac{\left|d\left(u, T x_{2 k+1}\right)\right||d(u, S u)|}{\left|1+d\left(u, x_{2 k+1}\right)\right|} \\
& +E \frac{\left|d\left(x_{2 k+1}, T x_{2 k+1}\right)\right|\left|d\left(x_{2 k+1}, S u\right)\right|}{\left|1+d\left(u, x_{2 k+1}\right)\right|} .
\end{aligned}
$$

Notice that $\lim _{n \rightarrow \infty}\left|d\left(u, x_{2 k+2}\right)\right|=\lim _{n \rightarrow \infty}\left|d\left(x_{2 k+1}, u\right)\right|=\left|d\left(x_{2 k+1}, S u\right)\right|=0$. Hence $\mid d(u$, $S u) \mid=0$, that is, $u=S u$. It follows similarly that $u=T u$. For uniqueness, assume that $u^{*}$ in $\overline{B\left(x_{0}, r\right)}$ is a second common fixed point of $S$ and $T$. Then

$$
\begin{aligned}
\left|d\left(u, u^{*}\right)\right| \leq & A\left|d\left(u, u^{*}\right)\right|+B \frac{|d(u, S u)|\left|d\left(u^{*}, T u^{*}\right)\right|}{\left|1+d\left(u, u^{*}\right)\right|} \\
& +C \frac{\left|d\left(u^{*}, S u\right)\right|\left|d\left(u, T u^{*}\right)\right|}{\left|1+d\left(u, u^{*}\right)\right|} \\
& +D \frac{|d(u, S u)|\left|d\left(u, T u^{*}\right)\right|}{\left|1+d\left(u, u^{*}\right)\right|} \\
& +E \frac{\left|d\left(u^{*}, S u\right)\right|\left|d\left(u^{*}, T u^{*}\right)\right|}{\left|1+d\left(u, u^{*}\right)\right|} .
\end{aligned}
$$

Since $\left|1+d\left(u, u^{*}\right)\right|>\left|d\left(u, u^{*}\right)\right|$, so we have

$$
\left|d\left(u, u^{*}\right)\right| \leq(A+C)\left|d\left(u, u^{*}\right)\right|
$$


This is contradiction because $A+C<1$. Hence $u^{*}=u$. Therefore, $u$ is a unique common fixed point of $S$ and $T$.

By setting $S=T$ in Theorem 6, we get the following corollary.

Corollary 7 Suppose that $(X, d)$ is a complete complex valued metric space and $x_{0} \in X$. Let $0 \prec r \in \mathbb{C}$ and $A, B, C, D$ and $E$ be five nonnegative reals such that $A+B+C+2 D+2 E<1$. Let $T: X \rightarrow X$ satisfy

$$
\begin{aligned}
d(T x, T y) \precsim & A d(x, y)+B \frac{d(x, T x) d(y, T y)}{1+d(x, y)}+C \frac{d(y, T x) d(x, T y)}{1+d(x, y)} \\
& +D \frac{d(x, T x) d(x, T y)}{1+d(x, y)}+E \frac{d(y, T x) d(y, T y)}{1+d(x, y)}
\end{aligned}
$$

for all $x, y \in \overline{B\left(x_{0}, r\right)}$. If

$$
\left|d\left(x_{0}, T x_{0}\right)\right| \leq(1-\lambda)|r|
$$

where $\lambda=\max \left\{\frac{A+D}{1-B-D}, \frac{A+E}{1-B-E}\right\}$, then there exists a unique point $u \in \overline{B\left(x_{0}, r\right)}$ such that $u=T u$.

Remark 8 The conclusion of Theorem 6 remains true if the condition (2) is replaced by the condition $\left|d\left(x_{0}, T x_{0}\right)\right| \leq(1-\lambda)|r|$.

By choosing $E=0$ in Theorem 6, we get the following corollary.

Corollary 9 Suppose that $(X, d)$ is a complete complex valued metric space and $x_{0} \in X$. Let $0 \prec r \in \mathbb{C}$ and $A, B, C, D$ be four nonnegative reals such that $A+B+C+2 D<1$. Let $S, T: X \rightarrow X$ satisfy

$$
d(S x, T y) \precsim A d(x, y)+B \frac{d(x, S x) d(y, T y)}{1+d(x, y)}+C \frac{d(y, S x) d(x, T y)}{1+d(x, y)}+D \frac{d(x, S x) d(x, T y)}{1+d(x, y)}
$$

for all $x, y \in \overline{B\left(x_{0}, r\right)}$. If

$$
\left|d\left(x_{0}, S x_{0}\right)\right| \leq(1-\lambda)|r|
$$

where $\lambda=\max \left\{\frac{A+D}{1-B-D}, \frac{A}{1-B}\right\}$, then there exists a unique point $u \in \overline{B\left(x_{0}, r\right)}$ such that $u=S u=$ $\mathrm{Tu}$.

By setting $S=T$ in Corollary 9, we get the following corollary.

Corollary 10 Suppose that $(X, d)$ is a complete complex valued metric space and $x_{0} \in X$. Let $0 \prec r \in \mathbb{C}$ and $A, B, C, D$ be four nonnegative reals such that $A+B+C+2 D<1$. Let $T: X \rightarrow X$ satisfy

$$
d(T x, T y) \precsim A d(x, y)+B \frac{d(x, T x) d(y, T y)}{1+d(x, y)}+C \frac{d(y, T x) d(x, T y)}{1+d(x, y)}+D \frac{d(x, T x) d(x, T y)}{1+d(x, y)}
$$


for all $x, y \in \overline{B\left(x_{0}, r\right)}$. If

$$
\left|d\left(x_{0}, T x_{0}\right)\right| \leq(1-\lambda)|r|
$$

where $\lambda=\max \left\{\frac{A+D}{1-B-D}, \frac{A}{1-B}\right\}$, then there exists a unique point $u \in \overline{B\left(x_{0}, r\right)}$ such that $u=T u$.

By choosing $D=0$ in Theorem 6, we get the following corollary.

Corollary 11 Suppose that $(X, d)$ is a complete complex valued metric space and $x_{0} \in X$. Let $0 \prec r \in \mathbb{C}$ and $A, B, C$ and $E$ be five nonnegative reals such that $A+B+C+2 E<1$. Let $S, T: X \rightarrow X$ satisfy

$$
d(S x, T y) \precsim A d(x, y)+B \frac{d(x, S x) d(y, T y)}{1+d(x, y)}+C \frac{d(y, S x) d(x, T y)}{1+d(x, y)}+E \frac{d(y, S x) d(y, T y)}{1+d(x, y)}
$$

for all $x, y \in \overline{B\left(x_{0}, r\right)}$. If

$$
\left|d\left(x_{0}, S x_{0}\right)\right| \leq(1-\lambda)|r|
$$

where $\lambda=\max \left\{\frac{A}{1-B}, \frac{A+E}{1-B-E}\right\}$, then there exists a unique point $u \in \overline{B\left(x_{0}, r\right)}$ such that $u=S u=$ Tu.

By setting $S=T$ in Corollary 11, we get the following corollary.

Corollary 12 Suppose that $(X, d)$ is a complete complex valued metric space and $x_{0} \in X$. Let $0 \prec r \in \mathbb{C}$ and $A, B, C$, and $E$ be five nonnegative reals such that $A+B+C+2 E<1$. Let $T: X \rightarrow X$ satisfy

$$
d(T x, T y) \precsim A d(x, y)+B \frac{d(x, T x) d(y, T y)}{1+d(x, y)}+C \frac{d(y, T x) d(x, T y)}{1+d(x, y)}+E \frac{d(y, T x) d(y, T y)}{1+d(x, y)}
$$

for all $x, y \in \overline{B\left(x_{0}, r\right)}$. If

$$
\left|d\left(x_{0}, S x_{0}\right)\right| \leq(1-\lambda)|r|
$$

where $\lambda=\max \left\{\frac{A}{1-B}, \frac{A+E}{1-B-E}\right\}$, then there exists a unique point $u \in \overline{B\left(x_{0}, r\right)}$ such that $u=T u$.

Remark 13 By equating $A, B, C, D$, and $E$ to 0 in all possible combinations, one can derive a host of corollaries which include the Banach fixed point theorem for self-mappings on the closed ball in complex valued metric spaces.

By choosing $D=E=0$ in Theorem 6, we get the extension of Theorem 2.1 of [2] to the closed ball as follows.

Corollary 14 Suppose that $(X, d)$ is a complete complex valued metric space and $x_{0} \in X$. Let $0 \prec r \in \mathbb{C}$ and $A, B, C$ be three nonnegative reals such that $A+B+C<1$. Let $S, T: X \rightarrow X$ satisfy

$$
d(S x, T y) \precsim A d(x, y)+B \frac{d(x, S x) d(y, T y)}{1+d(x, y)}+C \frac{d(y, S x) d(x, T y)}{1+d(x, y)}
$$


for all $x, y \in \overline{B\left(x_{0}, r\right)}$. If

$$
\left|d\left(x_{0}, S x_{0}\right)\right| \leq(1-\lambda)|r|,
$$

where $\lambda=\frac{A}{1-B}$, then there exists a unique point $u \in \overline{B\left(x_{0}, r\right)}$ such that $u=S u=T u$.

By setting $S=T$ in Corollary 14, we get Corollary 2.3 of [16] on the closed ball as follows.

Corollary 15 Suppose that $(X, d)$ is a complete complex valued metric space and $x_{0} \in X$. Let $0 \prec r \in \mathbb{C}$ and $A, B, C$ be three nonnegative reals such that $A+B+C<1$. Let $T: X \rightarrow X$ satisfy

$$
d(T x, T y) \precsim A d(x, y)+B \frac{d(x, T x) d(y, T y)}{1+d(x, y)}+C \frac{d(y, T x) d(x, T y)}{1+d(x, y)}
$$

for all $x, y \in \overline{B\left(x_{0}, r\right)}$. If

$$
\left|d\left(x_{0}, T x_{0}\right)\right| \leq(1-\lambda)|r|,
$$

where $\lambda=\frac{A}{1-B}$, then there exists a unique point $u \in \overline{B\left(x_{0}, r\right)}$ such that $u=T u$.

By choosing $C=D=E=0$ in Theorem 6, we get the extension of Theorem 4 of [1] to the closed ball as follows.

Corollary 16 Suppose that $(X, d)$ is a complete complex valued metric space and $x_{0} \in X$. Let $0 \prec r \in \mathbb{C}$ and $A, B$ be nonnegative reals such that $A+B<1$. Let $S, T: X \rightarrow X$ satisfy

$$
d(S x, T y) \precsim A d(x, y)+B \frac{d(x, S x) d(y, T y)}{1+d(x, y)}
$$

for all $x, y \in \overline{B\left(x_{0}, r\right)}$. If

$$
\left|d\left(x_{0}, S x_{0}\right)\right| \leq(1-\lambda)|r|
$$

where $\lambda=\frac{A}{1-B}$, then there exists a unique point $u \in \overline{B\left(x_{0}, r\right)}$ such that $u=S u=T u$.

By setting $S=T$ in Corollary 16, we get Corollary 2.3 of [1] on the closed ball as follows.

Corollary 17 Suppose that $(X, d)$ is a complete complex valued metric space and $x_{0} \in X$. Let $0 \prec r \in \mathbb{C}$ and $A, B$ be nonnegative reals such that $A+B<1$. Let $T: X \rightarrow X$ satisfy

$$
d(T x, T y) \precsim A d(x, y)+B \frac{d(x, T x) d(y, T y)}{1+d(x, y)}
$$

for all $x, y \in \overline{B\left(x_{0}, r\right)}$. If

$$
\left|d\left(x_{0}, T x_{0}\right)\right| \leq(1-\lambda)|r|
$$

where $\lambda=\frac{A}{1-B}$, then there exists a unique point $u \in \overline{B\left(x_{0}, r\right)}$ such that $u=T u$.

As an application of Theorem 6, we prove the following theorem for two finite families of mappings. 
Theorem 18 If $\left\{T_{i}\right\}_{1}^{m}$ and $\left\{S_{i}\right\}_{1}^{n}$ are two finite pairwise commuting finite families of selfmapping defined on a complete complex valued metric space $(X, d)$ such that the mappings $S$ and $T$ (with $T=T_{1} T_{2} \cdots T_{m}$ and $S=S_{1} S_{2} \cdots S_{n}$ ) satisfy the contractive conditions (1) and (2), then the component maps of the two families $\left\{T_{i}\right\}_{1}^{m}$ and $\left\{S_{i}\right\}_{1}^{n}$ have a unique common fixed point.

Proof From Theorem 6, we can say that the mappings $T$ and $S$ have a unique common fixed point $u$ i.e. $T u=S u=u$. Now our requirement is to show that $u$ is a common fixed point of all the component mappings of both families. In view of pairwise commutativity of the families $\left\{T_{i}\right\}_{1}^{m}$ and $\left\{S_{i}\right\}_{1}^{n}$ (for every $1 \leq k \leq m$ ), we can write $T_{k} u=T_{k} T u=T T_{k} u$ and $T_{k} u=T_{k} S u=S T_{k} u$ which show that $T_{k} u$ (for every $k$ ) is also a common fixed point of $T$ and $S$. By using the uniqueness of common fixed point, we can write $T_{k} u=u$ (for every $k$ ) which shows that $u$ is a common fixed point of the family $\left\{T_{i}\right\}_{1}^{m}$. Using the same argument one can also show that (for every $1 \leq k \leq n) S_{k} u=u$. Thus the component maps of the two families $\left\{T_{i}\right\}_{1}^{m}$ and $\left\{S_{i}\right\}_{1}^{n}$ have a unique common fixed point.

By setting $T_{1}=T_{2}=\cdots=T_{m}=F$ and $S_{1}=S_{2}=\cdots=S_{n}=G$ in Theorem 18, we get the following corollary.

Corollary 19 Suppose that $(X, d)$ is a complete complex valued metric space and $x_{0} \in X$. Let $0 \prec r \in \mathbb{C}$ and $A, B, C, D$ and $E$ be five nonnegative reals such that $A+B+C+2 D+2 E<1$. Let $F, G: X \rightarrow X$ satisfy

$$
\begin{aligned}
d\left(F^{m} x, G^{n} y\right) \precsim & A d(x, y)+B \frac{d\left(x, F^{m} x\right) d\left(y, G^{n} y\right)}{1+d(x, y)}+C \frac{d\left(y, F^{m} x\right) d\left(x, G^{n} y\right)}{1+d(x, y)} \\
& +D \frac{d\left(x, F^{m} x\right) d\left(x, G^{n} y\right)}{1+d(x, y)}+E \frac{d\left(y, F^{m} x\right) d\left(y, G^{n} y\right)}{1+d(x, y)}
\end{aligned}
$$

for all $x, y \in \overline{B\left(x_{0}, r\right)}$ and

$$
\left|d\left(x_{0}, G^{n} x_{0}\right)\right| \leq(1-\lambda)|r|
$$

where $\lambda=\max \left\{\frac{A+D}{1-B-D}, \frac{A+E}{1-B-E}\right\}$, then there exists a unique point $u \in \overline{B\left(x_{0}, r\right)}$ such that $u=F u=$ Gu.

By setting $m=n$ and $F=G=T$ in Corollary 19, we get the following corollary.

Corollary 20 Suppose that $(X, d)$ is a complete complex valued metric space and $x_{0} \in X$. Let $0 \prec r \in \mathbb{C}$ and $A, B, C, D$ and $E$ be five nonnegative reals such that $A+B+C+2 D+2 E<1$. Let $T: X \rightarrow X$ satisfy

$$
\begin{aligned}
d\left(T^{n} x, T^{n} y\right) \precsim & A d(x, y)+B \frac{d\left(x, T^{n} x\right) d\left(y, T^{n} y\right)}{1+d(x, y)}+C \frac{d\left(y, T^{n} x\right) d\left(x, T^{n} y\right)}{1+d(x, y)} \\
& +D \frac{d\left(x, T^{n} x\right) d\left(x, T^{n} y\right)}{1+d(x, y)}+E \frac{d\left(y, T^{n} x\right) d\left(y, T^{n} y\right)}{1+d(x, y)}
\end{aligned}
$$

for all $x, y \in \overline{B\left(x_{0}, r\right)}$ and

$$
\left|d\left(x_{0}, T^{n} x_{0}\right)\right| \leq(1-\lambda)|r|
$$


where $\lambda=\max \left\{\frac{A+D}{1-B-D}, \frac{A+E}{1-B-E}\right\}$, then there exists a unique point $u \in \overline{B\left(x_{0}, r\right)}$ such that $u=$ Tu.

Now we give an example satisfying our main result.

Example 21 Let $X_{1}=\{z \in \mathbb{C}: \operatorname{Re}(z) \geq 0$ and $\operatorname{Im}(z)=0\}$ and $X_{2}=\{z \in \mathbb{C}: \operatorname{Re}(z)=$ 0 and $\operatorname{Im}(z) \geq 0\}$ and let $X=X_{1} \cup X_{2}$. Consider a metric $d: X \times X \rightarrow \mathbb{C}$ as follows:

$$
d\left(z_{1}, z_{2}\right)= \begin{cases}\frac{2}{3}\left|x_{1}-x_{2}\right|+\frac{i}{2}\left|x_{1}-x_{2}\right| & \text { if } z_{1}, z_{2} \in X_{1} \\ \frac{1}{2}\left|y_{1}-y_{2}\right|+\frac{i}{3}\left|y_{1}-y_{2}\right| & \text { if } z_{1}, z_{2} \in X_{2} ; \\ \frac{2}{9}\left(x_{1}+y_{2}\right)+\frac{i}{6}\left(x_{1}+y_{2}\right) & \text { if } z_{1} \in X_{1}, z_{2} \in X_{2} ; \\ \frac{i}{3}\left(x_{2}+y_{1}\right)+\frac{2 i}{9}\left(x_{2}+y_{1}\right) & \text { if } z_{1} \in X_{2}, z_{2} \in X_{1},\end{cases}
$$

where $z_{1}=x_{1}+i y_{1}, z_{2}=x_{2}+i y_{2} \in X$. Then $(X, d)$ is a complex valued metric space. Take $z_{0}=\frac{1}{2}+0 i$ and $r=\frac{1}{3}+\frac{1}{4} i$. Then

$$
\overline{B\left(z_{0}, r\right)}=\left\{z \in X_{1}: 0 \leq \operatorname{Re}(z) \leq 1\right\} \cup\left\{z \in X_{2}: 0 \leq \operatorname{Im}(z) \leq 1\right\}
$$

Define $S, T: X \rightarrow X$ by

$$
\begin{aligned}
& S z= \begin{cases}0+\frac{x}{4} i & \text { if } z \in X_{1} \text { with } 0 \leq \operatorname{Re}(z) \leq 1, \operatorname{Im}(z)=0 ; \\
\frac{5 x}{6}+0 i & \text { if } z \in X_{1} \text { with } \operatorname{Re}(z)>1, \operatorname{Im}(z)=0 ; \\
\frac{y}{5}+0 i & \text { if } z \in X_{2} \text { with } 0 \leq \operatorname{Im}(z) \leq 1, \operatorname{Re}(z)=0 ; \\
0+\frac{4 y}{5} i & \text { if } z \in X_{2} \text { with } \operatorname{Im}(z)>1, \operatorname{Re}(z)=0 ;\end{cases} \\
& T z= \begin{cases}0+\frac{x}{6} i & \text { if } z \in X_{1} \text { with } 0 \leq \operatorname{Re}(z) \leq 1, \operatorname{Im}(z)=0 ; \\
\frac{4 x}{5}+0 i & \text { if } z \in X_{1} \text { with } \operatorname{Re}(z)>1, \operatorname{Im}(z)=0 ; \\
\frac{y}{7}+0 i & \text { if } z \in X_{2} \text { with } 0 \leq \operatorname{Im}(z) \leq 1, \operatorname{Re}(z)=0 ; \\
0+\frac{5 y}{6} i & \text { if } z \in X_{2} \text { with } \operatorname{Im}(z)>1, \operatorname{Re}(z)=0 .\end{cases}
\end{aligned}
$$

By a routine calculation, one can verify that the mappings $S$ and $T$ satisfy the conditions (1) and (2) of Theorem 6 with $A=\frac{1}{6}, B=\frac{1}{24}, C=\frac{1}{2}, D=\frac{1}{25}$ and $E=\frac{1}{26}$. Hence $S$ and $T$ are contractions on $\overline{B\left(z_{0}, r\right)}$ and $0+0 i \in \overline{B\left(z_{0}, r\right)}$ is a unique common fixed point of mappings $S$ and $T$.

It is interesting to notice that $S$ and $T$ are not contractions on the whole space $X$ for $z_{1}=z_{2}=\frac{3}{2}+0 i \notin \overline{B\left(z_{0}, r\right)}$ as

$$
\begin{aligned}
d\left(S z_{1}, T z_{2}\right)= & \frac{1}{30}+\frac{1}{40} i \succ \frac{33,859}{3,744,000}+\frac{4,837}{156,000} i \\
= & A d\left(z_{1}, z_{2}\right)+B \frac{d\left(z_{1}, S z_{1}\right) d\left(z_{2}, T z_{2}\right)}{1+d\left(z_{1}, z_{2}\right)}+C \frac{d\left(z_{2}, S z_{1}\right) d\left(z_{1}, T z_{2}\right)}{1+d\left(z_{1}, z_{2}\right)} \\
& +D \frac{d\left(z_{1}, S z_{1}\right)\left(z_{1}, T z_{2}\right)}{1+d\left(z_{1}, z_{2}\right)}+E \frac{d\left(z_{2}, S z_{1}\right) d\left(z_{2}, T z_{2}\right)}{1+d\left(z_{1}, z_{2}\right)}
\end{aligned}
$$


Authors' contributions

All authors contributed equally and significantly in writing this paper. All authors read and approved the final manuscript.

\section{Author details}

'Department of Mathematics, COMSATS Institute of Information Technology, Chak Shahzad, Islamabad, 44000, Pakistan. ${ }^{2}$ Department of Mathematics, Khon Kaen University, Khon Kaen, 40002, Thailand. ${ }^{3}$ The Centre of Excellence in Mathematics, Commission on Higher Education (CHE), Sri Ayudthaya Road, Bangkok, 10400, Thailand.

\section{Acknowledgements}

The authors thank the editor and the referees for their valuable comments and suggestions, which improved greatly the quality of this paper. The research of the third author is supported by the Centre of Excellence in Mathematics, the Commission on Higher Education, Thailand.

Received: 13 November 2013 Accepted: 3 March 2014 Published: 20 Mar 2014

\section{References}

1. Azam, A, Fisher, B, Khan, M: Common fixed point theorems in complex valued metric spaces. Numer. Funct. Anal. Optim. 32(3), 243-253 (2011)

2. Rouzkard, F, Imdad, M: Some common fixed point theorems on complex valued metric spaces. Comput. Math. Appl. 64(6), 1866-1874 (2012)

3. Sintunavarat, W, Kumam, P: Generalized common fixed point theorems in complex valued metric spaces and applications. J. Inequal. Appl. 2012, 84 (2012)

4. Klin-eam, C, Suanoom, C: Some common fixed-point theorems for generalized-contractive-type mappings on complex-valued metric spaces. Abstr. Appl. Anal. 2013, Article ID 604215 (2013)

5. Abbas, M, Arshad, M, Azam, A: Fixed points of asymptotically regular mappings in complex-valued metric spaces. Georgian Math. J. 20(2), 213-221 (2013)

6. Abbas, M, Fisher, B, Nazir, T: Well-posedness and periodic point property of mappings satisfying a rational inequality in an ordered complex valued metric space. Sci. Stud. Res., Ser. Math. Inform. 22(1), 5-24 (2012)

7. Abbas, M, Ćojbašić Rajić, V, Nazir, T, Radenović, S: Common fixed point of mappings satisfying rational inequalities in ordered complex valued generalized metric spaces. Afr. Math. (2013). doi:10.1007/s13370-013-0185-z

8. Ahmad, J, Klin-Eam, C, Azam, A: Common fixed points for multivalued mappings in complex valued metric spaces with applications. Abstr. Appl. Anal. 2013, Article ID 854965 (2013)

9. Arshad, M, Karapınar, E, Ahmad, J: Some unique fixed point theorems for rational contractions in partially ordered metric spaces. J. Inequal. Appl. 2013, 248 (2013)

10. Arshad, M, Shoaib, A, Beg, l: Fixed point of a pair of contractive dominated mappings on a closed ball in an ordered dislocated metric space. Fixed Point Theory Appl. 2013, 115 (2013)

11. Arshad, M, Azam, A, Vetro, P: Some common fixed point results in cone metric spaces. Fixed Point Theory Appl. 2009, Article ID 493965 (2009)

12. Azam, A, Ahmad, J, Kumam, P: Common fixed point theorems for multi-valued mappings in complex-valued metric spaces. J. Inequal. Appl. 2013, 578 (2013)

13. Azam, A, Arshad, M: Common fixed points of generalized contractive maps in cone metric spaces. Bull. Iran. Math Soc. 35(2), 255-264 (2009)

14. Banach, S: Sur les opérations dans les ensembles abstraits et leurs applications aux équations intégrales. Fundam. Math. 3, 133-181 (1922)

15. Chandok, S, Kumar, D: Some common fixed point results for rational type contraction mappings in complex valued metric spaces. J. Oper. 2013, Article ID 813707 (2013)

16. Huang, L-G, Zhang, $X$ : Cone metric spaces and fixed point theorems of contractive mappings. J. Math. Anal. Appl. 332(2), 1468-1476 (2007)

17. Hussain, N, Shah, MH, Amini-Harandi, A, Akhtar, Z: Common fixed point theorems for generalized contractive mappings with applications. Fixed Point Theory Appl. 2013, 169 (2013)

18. Kadelburg, Z, Radenović, S: Generalized quasicontractions in orbitally complete abstract metric spaces. Fixed Point Theory 13(2), 527-536 (2012)

19. Kannan, R: Some results on fixed points. Bull. Calcutta Math. Soc. 60, 71-76 (1968)

20. Karapınar, E: Fixed point theorems in cone Banach spaces. Fixed Point Theory Appl. 2009, Article ID 609281 (2009)

21. Karapınar, E: Some nonunique fixed point theorems of Ćirić type on cone metric spaces. Abstr. Appl. Anal. 2010, Article ID 123094 (2010)

22. Kutbi, MA, Ahmad, J, Hussain, N, Arshad, M: Common fixed point results for mappings with rational expressions. Abstr. Appl. Anal. 2013, Article ID 549518 (2013)

23. Kutbi, MA, Azam, A, Ahmad, J, Di Bari, C: Some common coupled fixed point results for generalized contraction in complex-valued metric spaces. J. Appl. Math. 2013, Article ID 352927 (2013)

24. Nadler, SB Jr.: Multi-valued contraction mappings. Pac. J. Math. 30, 475-488 (1969)

25. Sintunavarat, W, Cho, YJ, Kumam, P: Urysohn integral equations approach by common fixed points in complex-valued metric spaces. Adv. Differ. Equ. 2013, 49 (2013)

26. Sitthikul, K, Saejung, S: Some fixed point theorems in complex valued metric spaces. Fixed Point Theory Appl. 2012, 189 (2012)

27. Imdad, M, Ali, J, Tanveer, M: Coincidence and common fixed point theorems for nonlinear contractions in Menger PM spaces. Chaos Solitons Fractals 42(5), 3121-3129 (2009)

10.1186/1687-1812-2014-67

Cite this article as: Ahmad et al : Common fixed point results for contractive mappings in complex valued metric spaces. Fixed Point Theory and Applications 2014, 2014:67 